\title{
Os discursos de homens jovens sobre 0 acesso aos serviços de saúde ${ }^{*}$
}

Michael Ferreira Machado ${ }^{1}$

Maria Auxiliadora Teixeira Ribeiro²

MACHADO, M.F.; RIBEIRO, M.A.T. Young men's discourses regarding access to healthcare services. Interface - Comunic., Saude, Educ., v.16, n.41, p.343-55, abr./jun. 2012.

This paper presents some reflections on the meanings produced by young men from a fishing community in the Northeast of Brazil about the use of primary health care services in their region. They are based on information obtained through participant observation, on data provided by the Municipal Health Department and on discussion groups conducted with the young men. It was observed that the consumption of alcohol and other psychoactive drugs is growing among the young men. In addition, lay knowledge of health care is preferred to the official care network, which is sought for only in case of worsening of the health conditions and/or severe pain. Thus, we point to the need of broadening the debate on masculinity in view of the commitment to man's health.

Keywords: Young men. Meaning production. Primary health care.
Apresentam-se algumas reflexões acerca dos sentidos produzidos por homens jovens de uma comunidade de pescadores no Nordeste do Brasil sobre uso dos serviços de atenção básica de sua região. Parte-se de informações obtidas por meio de observação participante, dos dados da Secretaria Municipal de Saúde e dos grupos de discussão realizados com os homens jovens. Identificou-se o crescente consumo de álcool e outras drogas psicoativas entre os jovens, e uma preferência, entre os membros da comunidade, em usar o conhecimento leigo de cuidados com a saúde, e não a rede oficial de assistência, recorrendo a esta só em caso de piora no quadro e/ou dor. Aponta-se a necessidade de se ampliar a reflexão sobre a masculinidade, tendo em vista o comprometimento com a saúde do homem.

Palavras-chave: Homens jovens. Produção de sentidos. Atenção primária à saúde.
"Texto resultante de pesquisa para obtenção do título de psicólogo aprovada pelo Comitê de Ética em Pesquisa da Universidade Federal de Alagoas.

Mestrando, Programa de Pós-graduação em Psicologia,

Departamento de Psicologia, Universidade Federal de Pernambuco.

Centro de Filosofia e Ciências Humanas. Av. da Arquitetura, $s / n$, $9^{\circ}$ andar. Cidade Universitária. Recife, $\mathrm{PE}$ Brasil. 50.740-550 michael.mmachado@ gmail.com

${ }^{2}$ Programa de Pósgraduação em Psicologia, Universidade Federal de Alagoas. 


\section{Introdução}

O objetivo do presente trabalho é refletir sobre a produção discursiva na relação entre os homens jovens e os serviços de saúde de uma comunidade tradicional pesqueira de artesãos, totalmente coberta pela Estratégia de Saúde da Família, no município de Maceió-AL.

A inserção dos pesquisadores naquela comunidade deu-se por meio de um projeto de pesquisa financiado pelo CNPq, desenvolvido em 2009, que permitiu a identificação do alto consumo de álcool e de outras drogas psicoativas entre os homens jovens, culminando com a morte de pescadores em decorrência desses mesmos consumos. Estes foram os mais importantes aspectos de saúde que geraram a pesquisa aqui apresentada.

Na literatura específica, pesquisadores de diferentes campos disciplinares buscam compreender os riscos diferenciados de adoecimento e de morte para homens e mulheres (Aquino, 2006). No ensejo dessas discussões, as investigações que enfocam a relação do homem com a saúde tornaram-se, ao longo das duas últimas décadas, objeto de estudo recorrente da academia e dos serviços de saúde do Brasil (Villela, Monteiro, Vargas, 2009; Schraiber, Gomes, Couto, 2005).

No campo da saúde do homem, essas pesquisas apontam que os homens, em geral, são mais expostos a situações insalubres de trabalho (Keijzer, 2003), consomem elevado índice de álcool e outras drogas (Bezerra, 2002), além de buscarem o confronto com as situações de risco, como característica estruturante na construção da identidade masculina, aliada a um sentimento de invulnerabilidade, o que implica taxas elevadas de morte com causas violentas (Keijzer, 2003; Valdés, Olavarría, 1998).

No Brasil, o documento "Indicadores e Dados Básicos para a Saúde - IDB 2006 Brasil", publicado, em 2008, pelo Instituto Brasileiro de Geografia e Estatística, em parceria com o Ministério da Saúde, é uma referência para a análise do quadro geral da saúde dos homens e dos índices de morbimortalidade masculina. O estudo explicita, pela primeira vez, o tema "Saúde do Homem" (Brasil, 2007).

Nessa edição do IDB, são apresentados os principais indicadores de morbimortalidade masculina, agregados por região, faixa etária, renda, entre outros critérios. O documento aponta que os homens jovens são aqueles que apresentam maiores índices de internação e morte por causas externas homicídio, violência e uso abusivo de drogas -, diretamente relacionados aos processos de socialização, que, em geral, estimulam comportamentos de risco em detrimento do cuidado de si e dos outros (Brasil, 2007).

Um desdobramento dessa prática social é a maior presença de homens nos serviços de urgência e emergência em relação aos serviços de atenção básica em saúde no Brasil, segundo dados do próprio Ministério da Saúde.

Estudos apontam que os homens, em geral, sofrem mais de condições severas e crônicas de saúde do que as mulheres, e possuem expectativa de vida menor (Brasil, 2007).

Esse quadro, sobre a população masculina no campo da saúde, aponta a necessidade de se ampliar a reflexão sobre as masculinidades em direção a uma compreensão dos comprometimentos da saúde do homem, já que, tradicionalmente, os estudos sobre os homens, no campo da saúde, concentram-se em três temáticas: sexualidade, reprodução e violência.

De maneira geral, as investigações mostram que os homens evitam os espaços dos serviços de saúde, sendo avessos à prevenção e ao autocuidado (Gomes et al., 2011; Gomes, Nascimento, Araújo, 2007).

Em agosto de 2009, foi lançada a Política Nacional de Atenção Integral à Saúde do Homem (PNAISH), um importante marco político do Ministério da Saúde, visando a inclusão dos homens na rede oficial de assistência à saúde no Brasil. A elaboração dessa política pública foi fundamentada no diagnóstico elaborado por: pesquisadores e profissionais de saúde, sociedades médicas de urologia, cardiologia, gastroenterologia, pneumologia e saúde da família, representantes dos conselhos de secretários de saúde, além de dados do DATASUS, no qual são apresentados relevantes indicadores sobre a saúde dessa parcela da população brasileira.

Diante desse panorama, fica a indagação sobre quais são os sentidos produzidos pelos homens sobre os serviços de saúde, em particular, homens jovens de uma comunidade pesqueira, no município de Maceió. 
${ }^{3}$ MACEIÓ. Secretaria Municipal de Saúde. Panorama das equipes do PSF em Maceio-AL. Bol. Inform., ago. 2010. (Documento de circulação interna da secretaria)
Embora haja uma ampla discussão sobre masculinidade na área da saúde, em geral, ainda há uma insuficiência de estudos sobre o comprometimento masculino voltado para o estilo de vida saudável e a promoção da saúde (Gomes, 2008).

É, também, a partir da dimensão de gênero e das transformações nas relações e redes sociais - muitas delas decorrentes do movimento feminista - que é proposta uma abordagem também do masculino, pois tanto homens quanto mulheres necessitam ser compreendidos em sua singularidade e em sua diversidade, no âmbito das relações que estabelecem (Gomes, 2003).

Ao se focalizarem os temas da prevenção e da promoção da saúde, pode-se identificar que os efeitos do movimento de incluir o homem no debate sobre saúde não se restringem à saúde masculina. No movimento de inclusão dos homens e no comprometimento com a saúde da rede familiar, em que ele está inserido, conseguem-se ganhos tanto na saúde da mulher, quanto da criança, a partir de outras configurações de paternidade (Lyra-da-Fonseca, 2008; Keijzer, 2003).

\section{Contexto da pesquisa}

O município de Maceió possui o menor índice de cobertura populacional atendida pelo Programa de Saúde da Família no Estado de Alagoas. Segundo dados do Departamento de Atenção Básica do Ministério da Saúde, a cobertura populacional foi de $26,88 \%$ no ano de 2010 .

A comunidade onde vivem os participantes da pesquisa tem seu território tombado pelo Estado de Alagoas, segundo o Decreto n 33.225 de 14 de novembro de 1988, considerado patrimônio histórico, arquitetônico e urbanístico. É o único bairro de Maceió totalmente coberto pela Estratégia de Saúde da Família. Sua população, caracterizada por ser uma comunidade de pescadores artesanais, com um grande número de adolescentes e adultos jovens (Maceió, $2000)^{3}$, tinha 2.231 habitantes no senso do ano 2000. Localiza-se entre dunas, no encontro das lagoas Mundaú e Manguaba com o mar, ao sul do município de Maceió-AL. Têm a confecção da renda do filé e a pesca artesanal como principais fontes de renda e elementos identitários.

O bairro caracteriza-se como uma comunidade, com fortes vínculos familiares, que podem ser compreendidos nas relações entre os moradores, como fica exemplificado neste fragmento de fala durante uma das observações dos participantes: "aqui no Pontal todo mundo é família, todo mundo é parente de todo mundo, todo mundo é família (sic)".

\section{Método da pesquisa}

Essa pesquisa é caracterizada como um estudo qualitativo, participativo, exploratório (Minayo, 2009). Homens jovens, com idade entre vinte e trinta anos, residentes no Pontal da Barra, Maceió - Alagoas, Brasil, fizeram parte deste estudo. A formulação das informações seguiu três etapas:

Primeiramente, foi realizada a observação participante com os moradores jovens da comunidade do Pontal da Barra, segundo a formulação de Montero (2006), que a define como uma estratégia de entrada no campo que visa conhecer os fenômenos, eventos e circunstâncias de um determinado grupo. Fenômenos aos quais o pesquisador não tem acesso, caso não esteja inserido no grupo.

A inserção na comunidade ocorreu no início do ano de 2009, as observações participantes com recorte de homens e saúde foram realizadas no segundo trimestre de 2010, em particular, nos espaços públicos e locais com aglomeração 
de homens jovens, como o porto. O contato deu-se por meio de conversas informais sobre assuntos corriqueiros. As informações foram registradas em diário de campo, segundo o modelo de Brandão (1982).

Na segunda etapa, foi realizada a observação participante, quando cinco homens jovens foram convidados para as rodas de discussão, que ocorreram à noite, em função do horário de trabalho, na escola da comunidade, devido à necessidade de um local que facilitasse a audiogravação das discussões.

As rodas de discussão foram organizadas como espaços de interação social, promovendo a fala e a valorização da palavra. Essa prática discursiva possibilita aos atores sociais construírem e darem sentido à realidade que os cerca (Flick, 2002; Spink, 2000).

Os temas debatidos nos encontros foram propostos com base nas informações produzidas durante as observações participantes e nos diálogos sobre saúde obtidos nas conversas informais. Ao final de cada roda de discussão, ocorreu um momento de avaliação. Foram realizados três encontros, com duração média de trinta minutos, nos quais as falas foram audiogravadas e, posteriormente, transcritas.

Vale também ressaltar que, para preservar o anonimato, os sujeitos participantes foram nomeados com nomes de santos católicos, populares no Brasil, a saber: Antônio, João, Pedro, José e Jorge.

A terceira etapa foi composta pela busca de informações sobre a comunidade, junto aos informantes privilegiados, como a equipe de saúde da família que atende essa população e a Secretaria Municipal de Saúde. Pessoas que, devido a sua posição e ao tempo de permanência nas instituições, detêm um conhecimento aprofundado das informações e das rotinas de atividades ali desenvolvidas (Passos et al., 2004). Além disso, foi realizada uma pesquisa em arquivos públicos e nas agências governamentais, nos dados disponibilizados eletronicamente.

As informações foram analisadas a partir da perspectiva teórica das práticas discursivas e produção de sentidos no cotidiano, fundamentadas no construcionismo social (Spink, 2000).

\section{Conversa com a literatura}

Com base nas informações construídas com os participantes, buscaram-se interlocutores na literatura que auxiliassem na compreensão dos sentidos, fazeres e práticas em saúde por esses homens jovens. Dessa forma, buscaram-se autores que se pautaram em suas pesquisas na Psicologia Social Discursiva, como Simião (2010), nos teóricos do construcionismo social e das práticas discursivas, como Spink (2004) e Gergen (1985), além das reflexões acerca das masculinidades, de Machado, Ribeiro e Martins (2010).

A Psicologia Social Discursiva pode ser compreendida como a utilização dos pressupostos da Análise do Discurso no estudo de temas relevantes à Psicologia Social, tendo como uma das principais características a ideia de discurso como elemento produtor de realidades e agente de práticas sociais (Simião, 2010).

A impossibilidade de "personificação" da masculinidade dominante é aqui entendida como ideal de virilidade, marcada por relações desiguais de poder, fortemente hierarquizado; a partir dessa perspectiva, faz-se necessário compreender e buscar, em seus contextos, como os homens atualizam o modelo hegemônico de masculinidade, considerando a rede de relações e práticas sociais por eles estabelecidas em seu cotidiano (Machado, Ribeiro, Martins, 2010).

O construcionismo social privilegia a linguagem e o discurso como objeto de estudo, sendo estes compreendidos como ações pelas quais as pessoas descrevem e explicam o mundo em que vivem (Gergen, 1985). Outra reflexão valorosa do construcionismo social é a afirmação de que o conhecimento é uma prática social, produzida coletivamente e localizada historicamente (Spink, 2004).

E por fim, fundamenta-se nas práticas discursivas e produção de sentidos no cotidiano, em especial em Spink (2000), ao considerar que os sentidos são construídos socialmente, em um empreendimento coletivo, mais precisamente interativo, por meio do qual as pessoas constroem os termos a partir dos quais compreendem e lidam com as situações e fenômenos a sua volta, sendo o motor da ação humana (Spink, 2004). 


\section{Compreendendo sentidos}

Com base nas transcrições das rodas de discussão, foram realizadas leituras sistemáticas das mesmas, com o intuito de se identificarem aproximações e distanciamentos nos argumentos produzidos nas conversas.

Após esse exercício, construíram-se quatro eixos de análise dos discursos: o primeiro, sobre os sentidos dos cuidados em saúde; o segundo, sobre as práticas apontadas como nocivas à saúde; o terceiro, sobre os homens e os usos da rede pública de saúde, em especial, os sentidos sobre a Unidade de Saúde, que atende à comunidade; e o último eixo, que apresenta os sentidos produzidos sobre os problemas de saúde existentes na comunidade.

\section{Sentidos dos cuidados em saúde}

Este eixo está relacionado: aos cuidados no campo da saúde, aos processos de socialização na comunidade, às ações coletivamente compartilhadas, entre os seus membros, nesse campo.

Indagados sobre quais são as ações realizadas quando apresentam algum problema de saúde, surgem falas que demonstram as práticas cotidianas de cuidados em saúde, exemplificadas nesses recortes: "quando pode procura o posto de saúde, se o remédio der certo, a gente procura o remédio, mas quando não dá a gente tem que procurar o posto, né?" (Antônio). "[...] trata em casa mesmo. Agora, vai ver se não dá jeito, aí procura o posto" (Pedro).

Eles narram que, inicialmente, procuram os saberes tradicionais e a farmácia. Só procuram o saber médico quando avaliam que a situação é mais grave, conforme Jorge " [...] quando a doença é assim uma gripe ou uma coisa dessa maneira faz um chá [...], mas quando você vê que a coisa é mais urgente, aí levo pro médico" (Jorge). A procura pelo alívio aos incômodos que os afligem demonstra a existência de um saber em saúde, que circula entre os membros da comunidade, para além da rede oficial de assistência.

Acerca dos cuidados-assistência à saúde, este é sempre expresso como uma função das mulheres: "quando alguém adoece quem toma conta [...] são as irmãs, a mãe ou a avó" (João).

Os homens aparecem em um papel secundário/apoio, já que quem acompanha os enfermos nas unidades de saúde são as mulheres, pois a elas cabe o cuidado mais incisivo. A atuação masculina relatada pelos participantes é, em sua maioria, um "apoio logístico", ou seja, o homem é aquele que leva a esposa e/ou mãe, junto com o/a enfermo/a, para os serviços de saúde oficiais. Isso pode apontar outras formas de cuidado, se ampliarmos sua definição.

Os discursos também apresentam o argumento da prevenção, como uma característica importante para manter-se saudável: "evitar doenças, várias coisas que influi muito também" (José) - mas as ações vão na direção oposta à prevenção, mesmo quando realizam práticas esportivas, como o surfe. Isso porque alia-se a prática de atividades físicas - em particular, no caso do futebol - com o consumo do álcool, mesmo este sendo considerado um problema para a saúde. Nos finais de semana e folgas, "eu bebo umas, uma dúzia (risos)" (José).

\section{Práticas apontadas como nocivas à saúde}

Uma problemática identificada durante as observações participantes foi o alto consumo de álcool e do tabaco entre os jovens. Nos espaços públicos existentes, onde se concentra uma grande quantidade de homens jovens, nos fins de tarde, nos feriados e finais de semana, a interação se dá mediada pelo consumo abusivo de bebidas alcoólicas e de cigarros.

Em suas falas, eles apresentam essa prática como nociva à saúde: "o homem saudável é o que não usa bebida porque a primeira coisa que destrói a saúde do homem é o álcool" (José). Também narram que os primeiros contatos com as bebidas alcoólicas e com o tabaco se dão na família, como fala José: "a bebida é mais fácil que o cigarro, é muitas vezes através da bebida que você começa com o cigarro, dificilmente você só começa com o cigarro, primeiro vem logo a bebida"; e "eu comecei no cigarro por causa da minha mãe, teve um dia que eu achei interessante e vou provar; até hoje" (Pedro). 


\section{Homens e usos da rede pública de saúde}

Este eixo aborda os sentidos produzidos pelos participantes e as relações estabelecidas com a rede de saúde pública que atende a população.

Eles relatam que, comumente, não procuram a assistência dos serviços de saúde, como Antônio: "se eu precisasse de um médico aí eu iria [...] a maioria do pessoal só procura o médico quando tá ruim mesmo, quando o caso não tem mais futuro". Ou como na explanação de Pedro: "muitas vezes é assim, só vai no médico quando está sentindo uma dor, quando não tá sentindo, acha que está tudo bem"; e como Jorge: "eu vou quando aparece alguma coisa, aí eu vou, né? Até agora eu to em forma" (Pedro).

Apresentam, também, a precariedade dos serviços públicos, em particular, a Unidade Básica de Saúde que não atende às demandas: "a gente vai lá e não é atendido, mofa pra pegar uma ficha" (Jorge); e "principalmente nesse posto aqui" (José).

Sobre o horário de atendimento e o funcionamento da Unidade Básica de Saúde da Família (U.B.S.F.), surgem considerações como: "você tem que chegar cedinho, pra poder pegar uma ficha, pra ser atendido" (João). Segundo esse relato, este aspecto é um dos obstáculos relevantes para a procura do sistema de saúde.

Outro elemento é a falta de profissionais: "falta médico, falta pessoal, falta tudo, a gente quer ajeitar um dente e muitas vezes o aparelho está quebrado" (José); e a dificuldade, também, nos atendimentos para além da Unidade de Saúde da comunidade: "toda a vez que eles dão esse encaminhamento faz a gente andar demais" (Pedro); e "até a ambulância aqui a maresia acabou todinha" (João).

Vale esclarecer que essa expressão, "andar demais", diz respeito à peregrinação à qual os usuários são submetidos, em decorrência da desarticulação da rede de saúde. Esse fragmento de fala, anotado em uma das observações participantes, é um exemplo: "você tem que ir em quatro lugares diferentes para fazer um exame de sangue; fazer jejum quatro dias é complicado" (sic).

\section{Identificação dos problemas comunitários de saúde}

O quarto eixo diz respeito à identificação dos problemas de saúde existentes na comunidade. Como membros de uma comunidade pequena, em que os laços familiares são bastante fortes, a maioria das atividades diárias e laborais é desenvolvida na comunidade. Esse contexto contribui para a visibilidade dos problemas concernentes à saúde desse grupo. Nas falas, foram enumeradas algumas doenças ou surtos epidêmicos, como: a dengue, as viroses, o consumo das drogas ilícitas, o HIV/Aids.

Essa enumeração dos problemas comunitários é relevante, pois a UBSF, por meio da Estratégia de Saúde da Família (ESF), é a principal porta de entrada da rede do Sistema Único de Saúde (SUS). Além disso, uma das diretrizes da Política Nacional de Atenção Integral à Saúde do Homem prevê ações na ESF (Brasil, 2007), e esse sentimento de pertencimento ao lugar, ou visão geral acerca dos problemas que afetam a comunidade, é importante para a mobilização desses atores em ações de promoção da saúde.

\section{Refletindo os sentidos produzidos nas falas}

Dessa forma, levando-se em consideração como os sujeitos e coletividades organizam suas formas de vida, elaborando estratégias para suprir as suas necessidades, os aspectos pertencentes à ordem coletiva precisam ser incluídos na reflexão sobre os cuidados em saúde.

No caso de homens jovens, que estão no ápice das aptidões orgânicas e físicas, constitui-se um verdadeiro desafio tecer reflexões em relação à saúde e trabalhar numa perspectiva de promoção de saúde e hábitos saudáveis, ampliando-se a orientação para além de uma postura prescritiva.

O desafio está em tornar as iniciativas governamentais de saúde significativas para o público-alvo das ações, já que, por exemplo, no grupo investigado, a procura pelos cuidados com a saúde é direcionada, inicialmente, para as práticas tradicionais, como receitas caseiras.

Em relação às ações realizadas e ao conhecimento disponível na rede oficial de saúde, a busca por parcerias com outros saberes torna-se importante quando se visa uma integralidade das ações, e não 
apenas na adesão ao serviço, e se produzem novas relações com o campo da saúde, pois existem saberes de/sobre saúde que circulam nas conversas cotidianas das relações familiares, "o problema de sinusite é doencinha de pobre mesmo [...] e pra curar tem que ser com chá de batatinha [...] só cura com remédio caseiro" (José).

Os estabelecimentos dos serviços de saúde, também nesse grupo estudado, não são identificados como espaços públicos de circulação para os homens, como fica expresso nestas falas: "eu nunca fui nesse posto" (Pedro) e "você olha nesse posto, tá uma fila aí, idoso, a maioria idoso..." (José). Os espaços das unidades de saúde são reconhecidos e compreendidos como infantis e/ou feminilizados, ou para idosos.

Historicamente, os serviços ofertados nas unidades de saúde são voltados para a saúde maternoinfantil e/ou, a partir dos anos de 1980, para a população idosa (Couto et al., 2010), levando os homens a assumirem o posicionamento de distanciamento em relação a esses ambientes (Figueiredo, Schaiber, 2011).

Essas falas sinalizam a construção social da masculinidade nessa comunidade, pois um dos aspectos do discurso sobre a formação do masculino é que ele se constitui em oposição ao feminino, mesmo ao ponderarem que homens e mulheres podem ter características tanto masculinas como femininas.

A respeito dessa caracterização, convém ainda considerar a reflexão de Fernández (2001) sobre o homem que, em um sentido estrito, é uma designação para os sujeitos possuidores de características sexuais específicas, produzidas culturalmente, seguindo determinados padrões que os fazem serem reconhecidos como homens, mesmo quando se considera que o par relacional masculino-feminino possui fluidez e não se reduz à anatomia.

Indagados sobre se iam ao posto de saúde, justificavam a ação de não procura no par relacional homem-mulher,

"eu não sei, eu acho que é porque a mulher ela sente mais, ela é mais sensível [...] porque mulher tem que ter sempre tratamento, sempre tem que ir ao médico, pra saber se está bem [...] o homem não, o negócio dele é trabalhar, como diz: é mais bruto, né?". (Antônio)

Essas falas apresentam o sentido de que as práticas de prevenção e promoção são atribuições das mulheres.

As construções culturais de gênero contribuem para a formação de posicionamentos acerca do que é ser homem e ser mulher, ocorrendo aproximações e afastamentos dos padrões que predominam no(s) contexto(s) vivido(s), já que, em uma mesma conjuntura, podem existir diversos modelos de gênero e, dentre eles, haver um hegemônico, fazendo com que não se exclua a possibilidade de flexibilizações e/ ou negociações sobre o que se entende por masculino e por feminino (Gomes, Rebelo, Nascimento, 2010).

Com referência aos cuidados com a saúde, são desenvolvidas algumas atividades, sobretudo atividades esportivas, como o futebol e o surfe. Mas a problemática é acerca dos empreendimentos pessoais, quando se fala da adesão à rede de saúde: "rapaz, faz um bocado de tempo ját que fui nesse posto" (Jorge).

Paralelamente a essas considerações, vêm os movimentos de reflexão sobre o corpo e a necessidade de cuidados: "eu comecei a fumar quando eu tinha 13 anos, to com vinte e quatro, fumei que não era brincadeira, sempre você fica com falta de ar, entendeu? Quando você pega a onda e leva o caldo [...] você fica em baixo d'água um ou dois minutos, já fica sufocado" (Pedro); e "tava me ofendendo, me deixando muito cansado e aí eu deixei" (José). Aqui está presente a contradição entre o cuidado (prática esportiva) e o descuido (fumo).

Em todas as famílias dos participantes nas rodas de discussão, ou eram fumantes, e/ou ex-fumantes, ou os pais fumam/fumaram e eles, também, narram a dificuldade de abandonar o uso do tabaco: "e pra deixar também é muito difícil, se você não tiver força de vontade" (José). Quando associa o uso do álcool com o tabaco, um dos participantes retroalimenta o consumo da outra substância: "assim, eu passo dois dias para fumar uma carteira de cigarro e quando eu to bebendo eu fumo duas, três por dia, isso bebendo, entendeu?" (Pedro). 
O alto consumo de álcool se inicia nas famílias, nos processos de socialização na infância, assim como ocorre em outros grupos e contextos; essa questão é corroborada por Bezerra (2002), que estudou a relação entre distúrbios psiquiátricos e o consumo de álcool na atividade pesqueira em Belém, no Pará.

Outro ponto importante para a compreensão dos sentidos produzidos acerca da saúde e que chama a atenção, é que, nessa comunidade, o álcool também funciona como forma de pagamento para uma atividade laboral: "tem gente assim, que se você mandar limpar um quintal e der um litro pra ele, eles vão" (Pedro).

Sobre a rede de saúde, uma questão que deve ser discutida é a invisibilidade dos homens nesses locais. Uma reflexão sobre a estruturação e a organização da rede de saúde é válida, independentemente da política pública de saúde à qual a pessoa esteja vinculada. Os encaminhamentos e a desarticulação entre os níveis de atenção acarretam o abandono do tratamento, como aconteceu com Pedro: "agora fica fazendo a pessoa andar [...] eu não podia faltar ao trabalho". Esse relato fomenta a discussão sobre o atendimento à população e a carência de oferta de serviços com qualidade, adequados às necessidades em saúde, bem como a reorganização na atenção e na estruturação de uma rede entre usuários, comunidade/território e serviços de saúde.

A invisibilidade dos homens é uma prática recorrente no cotidiano dos serviços de saúde (Gomes et al., 2011). Couto et al. (2010), em pesquisa realizada em quatro estados brasileiros, ressaltam a insatisfação dos usuários homens com a atenção oferecida na rede de assistência, e a precariedade nos serviços das unidades, gerando, assim, uma evasão nos serviços de atenção básica (Gomes et al., 2011).

Além dos desafios na prestação de serviços de qualidade no SUS, na ausência dos homens nos serviços de saúde, o fator trabalho é importante; esse determinante é a justificativa utilizada pelos homens para não procurarem os serviços de saúde: "o cansaço do trabalho também" (Antônio). Figueiredo e Schraiber (2011) afirmam que o trabalho é um elemento constituinte das masculinidades; assim, considerar essa variável na organização e funcionamento dos estabelecimentos de atenção básica em saúde se faz necessário. Essa ponderação não está relacionada apenas aos homens e, sim, a todas as pessoas inseridas no mercado de trabalho.

\section{Algumas considerações}

Entre os comunitários participantes do estudo, os valores tradicionais sobre a constituição do masculino estão presentes nas práticas discursivas dos homens jovens e identificados nas relações de gênero, no campo da atenção e no cuidado em saúde.

A discussão com os participantes desta pesquisa corrobora com as indagações encontradas em alguns estudos sobre homens e o modelo hegemônico de masculinidade (Villela, Monteiro, Vargas, 2009), porém, amplia a discussão com a apresentação de novas considerações.

Na literatura, encontramos que os homens são avessos aos cuidados com a saúde (Simião, 2010; Schraiber, Gomes, Couto, 2005), entretanto, os colaboradores do estudo identificam a procura inicial das práticas de atenção em saúde nas relações familiares.

Os homens jovens da comunidade relatam algumas limitações no atendimento e no serviço oferecido na unidade de saúde que atende essa população. A partir das falas e das observações participantes, é possível conjeturar modificações que visem a uma participação dos homens nas unidades de saúde, em particular, mudanças nas estratégias educativas dos estabelecimentos oficiais de assistência à saúde e na capacitação/qualificação contínua de equipes de profissionais de saúde, indo além do atendimento a essa parcela da população, pois as práticas de comunicação e educação em saúde não consideram, em sua maioria, os saberes e fazeres existentes entre os/as usuários/as, sendo marcadas pelo autoritarismo (Schraiber et al., 2010).

Outro aspecto a ser levado em conta para a compreensão das práticas em saúde dos participantes é a invisibilidade das ações desenvolvidas pela equipe da ESF. Eles relatam que o único contato que têm com esses profissionais é no controle epidemiológico da dengue, quando os agentes comunitários e os agentes de endemias realizam as visitas domiciliares para o controle do vetor de transmissão, conforme 
diz José: "[...] esse negocio da dengue mesmo, atacam mais, aí eles (agente comunitários) passam aqui de vez em quando, só nessa época mesmo [...] só em tempo de dengue mesmo".

Esse quadro leva a considerar que há um distanciamento entre os serviços oferecidos pela atenção básica em saúde e os problemas de saúde dos homens jovens participantes do estudo, ou seja, um afastamento entre empreendimentos governamentais de saúde e a população masculina jovem da comunidade. As ações realizadas pelos agentes comunitários de saúde são identificadas como direcionadas para a coletividade e distantes das necessidades dos jovens, assim como as práticas dos profissionais de saúde existentes na unidade.

Levando-se em conta que os cuidados de saúde relatados pelos jovens deste estudo, são, inicialmente, caseiros, e em vista de uma integralidade das ações em saúde, para essa população, é possível conjeturar sobre a realização de parcerias com saberes e práticas de cuidado em saúde tradicionais, seja por meio dos agentes comunitários de saúde, ou de outros atores existentes no território.

A viabilidade de ações que transponham os muros da Unidade Básica de Saúde, valorizando e potencializando saberes e fazeres saudáveis, como as práticas esportivas, exemplificadas pelo futebol e o surfe, também poderia ser considerada.

Como esse estudo caracteriza-se como uma pesquisa participativa, alguns movimentos decorrentes das rodas de discussão foram significativos, como: espaços de elaboração e ponderação sobre os empreendimentos pessoais e coletivos para se ter uma vida saudável ou uma certa "qualidade de vida". Isso porque, discursivamente, os homens participantes do estudo costumam posicionar-se acerca da saúde como um modelo ideal, mas não trazem essas reflexões para a sua vida e só recorrem ao auxílio da rede oficial de saúde quando há piora do quadro ou quando a dor é contínua.

Desse modo, é importante destacar que, entre os colaboradores da pesquisa, o ideal de virilidade, agrupado ao sentimento de invulnerabilidade ao adoecimento, afasta os homens dos estabelecimentos de saúde, mesmo existindo um movimento de reflexão sobre as suas más condições de saúde, consequente de algumas práticas por eles descritas como prejudiciais e consideradas pouco saudáveis, iniciadas no ambiente doméstico, no âmbito das relações familiares.

Em Alagoas, segundo os números do Ministério da Saúde, da Secretaria Estadual de Saúde e do IBGE, no recorte dos anos de 2008 e 2009, a maioria da população tem a rede do SUS como único caminho de acesso de atenção à saúde. Entre outros fatores determinantes desse quadro, um deles é a crítica condição socioeconômica da maioria da população do Estado. Dessa forma, para ampliar a discussão, considera-se a importância da estruturação do fluxograma da rede de saúde e dos cuidados oferecidos à população, além dos insumos do Ministério da Saúde, para práticas assertivas de prevenção de doenças e promoção da saúde.

Talvez seja possível traçar os desafios para alguns segmentos, como os dos homens que trabalham na pesca, assim como os cortadores de cana-de-açúcar, que, segundo dados do Sindicato dos Produtores de Açúcar e Álcool de Alagoas (2007), somam setenta mil trabalhadores, os quais, devido à exaustiva jornada de trabalho e à necessidade de uma grande força física, são, em sua maioria, homens; e, também, os demais trabalhares rurais e os jovens da periferia.

Dessa forma, pondera-se que, para se atingir uma integralidade na atenção à saúde da população masculina, devem ser considerados outros aspectos estruturais, para além das relações de gênero, como: idade, condição socioeconômica, os determinantes sociais de saúde, os contextos culturais e as formas de vida - entendendo-se a saúde como uma produção social múltipla e complexa (Brasil, 2007), sendo uma parcela da vida das pessoas, e partindo-se do posicionamento de que as masculinidades são construídas historicamente, em um processo constante de transformação.

As manifestações da masculinidade hegemônica, presentes nos discursos, lançam desafios para a inclusão dessa população na rede de saúde. A Política Nacional de Atenção Integral à Saúde do Homem convoca os atores e instituições dos serviços de saúde no Brasil a debaterem essa temática. Da mesma maneira como as outras políticas públicas direcionadas a grupos sociais discriminados são marcos políticos importantes, as políticas de saúde devem ser efetivadas visando uma melhoria do SUS, em especial, a partir dos seus princípios básicos norteadores, e não como uma carga a mais em um sistema sobrecarregado. 
A equidade e a necessidade de serviços que atendam às demandas da população tornam iminente a estruturação de uma rede entre os usuários, a sua comunidade/território e os serviços de atenção à saúde, por meio de um compromisso ético na utilização dos protocolos e da reorganização do atendimento, possibilitando a renovação destes, visando uma atenção integral.

\section{Colaboradores}

Os autores trabalharam juntos em todas as etapas de produção do manuscrito.

\section{Referências}

AQUINO, E.M.L. Gênero e saúde: perfil e tendências da produção científica no Brasil. Rev. Saude Publica, v. 40, n.esp., p.121-32, 2006. Disponível em: $<$ http://www.scielo.br/scielo.php?script=sci_arttext\&pid= S003489102006000400017\&lng =en\&nrm =iso > . Acesso em: 5 mar. 2010. doi: 10.1590/S0034-89102006000400017.

ALAGOAS. Decreto $n^{\circ} 33.225$, de 14 de novembro de 1988. Dispõe sobre tombamento do núcleo urbano do bairro do Pontal da Barra e dá outras providências. Maceió: Imprensa Oficial Graciliano Ramos, 1988.

BEZERRA, B.P. A saúde mental no nordeste da Amazônia: estudo de pescadores artesanais. 2002. Tese (Doutorado em Psiquiatria) - Escola Paulista de Medicina, Universidade Federal de São Paulo, São Paulo. 2002.

BRANDÃO, C.R. Diário de campo: a antropologia como alegoria. São Paulo: Brasiliense, 1982.

BRASIL. Ministério da Saúde. Secretaria de Atenção à Saúde. Departamento de Atenção Básica. Teto, credenciamento e implantação das estratégias de Agentes Comunitários de Saúde, Saúde da Família e Saúde Bucal. Competência: junho de 2010. Brasília: Ministério da Saúde, 2010.

. Departamento de Ações Programáticas Estratégias. Área Técnica de Saúde do Homem. Política Nacional de Atenção Integral à Saúde do Homem: princípios e diretrizes. Brasília: Ministério da Saúde, 2009.

. OPAS. IDB 2006 Brasil: indicadores e dados básicos para a saúde. Rede Interagencial de Informações para a Saúde (Ripsa). Brasília: Ministério da Saúde, 2007.

COUTO, M.T. et al. O homem na atenção primária à saúde: discutindo (in)visibilidade a partir da perspectiva de gênero. Interface - Comunic., Saude, Educ., v.14, n.33, p.257-70, 2010. Disponível em: <http://www.scielo.br/ scielo.php?script $=$ sci_arttext\&pid $=$ S1414-32832010000200003\&lng $=$ en\&nrm =iso $>$. Acesso em: 4 jan. 2012. http://dx.doi.org/10.1590/S141432832010000200003. 
FERNÁNDEZ, P.M. Masculinidad: ¿nuevas construcciones? O ¿más de lo mismo?. Disponível em: <http://www.hombresigualdad.com/nueva-masculinidad-nuevaconstruccion.pdf>. Acesso em: 20 maio 2010.

FIGUEIREDO, W.S.; SCHRAIBER, L.B. Concepções de gênero de homens usuários e profissionais de saúde de serviços de atenção primária e os possíveis impactos na saúde da população masculina, São Paulo, Brasil. Cienc. Saude Colet., v.16, suppl.1, p.935-44, 2011. Disponível em: <http://www.scielo.br/scielo.php? script=sci_arttext\&pid=S1413-81232011000700025\&lng=en\&nrm=iso > . Acesso em: 4 jan. 2012.

FLICK, U. An introduction to qualitative research. London: Sage, 2002.

GERGEN, K. The social constructionist movement in modern psychology. Am. Psychol., v.40, n.3, p.266-75, 1985.

GOMES, R. Sexualidade masculina, gênero e saúde. Rio de Janeiro: Editora Fiocruz, 2008. (Coleção Criança, Mulher e Saúde).

Sexualidade masculina e saúde do homem: proposta para uma discussão.

Cienc. Saude Colet., v.8, n.3, p.825-9, 2003. Disponível em:

$<$ http://www. scielo.br/scielo.php?script=sci_arttext\&pid= S141381232003000300017\&lng $=$ en\&nrm $=$ iso $>$. Acesso em: 6 mar. 2011. doi: 10.1590/S1413-81232003000300017.

GOMES, R. et al. Os homens não vêm! Ausência e/ou invisibilidade masculina na atenção primária. Cienc. Saude Colet., v.16, suppl.1, p.983-92, 2011.

Disponível em: <http://www.scielo.br/scielo.php?script=sci_arttext\&pid=S1413$81232011000700030 \& \operatorname{lng}=$ en\&nrm=iso $>$. Acesso em: 4 jan. 2012. http://dx.doi.org/10.1590/S1413-81232011000700030.

GOMES, R; NASCIMENTO, E. F.; ARAUJO, F. C. Por que os homens buscam menos os serviços de saúde do que as mulheres? As explicações de homens com baixa escolaridade e homens com ensino superior. Cad. Saude Publica, v.23, n.3, 2007 . Disponível em: <http://www.scielo.br/scielo.php?script=sci arttext\&pid $=$ S0102311X200700030001\&ng $=e n \& n r m=$ iso $>$. Acesso em: 24 maio 2012. http://dx.doi.org/10.1590/S0102-311X2007000300015.

GOMES, R.; REBELO, L.E.F.; NASCIMENTO, E.F. Medos sexuais masculinos e política de saúde do homem: lacunas e desafios. In: MEDRADO, B. et al. (Orgs.). Homens e masculinidades: práticas de intimidades e políticas públicas. Recife: Instituto Papai, 2010. p.95-108.

KEIJZER, B. Hasta donde el cuerpo aguante: género, cuerpo y salud masculina. In: CÁCERES, C.F. et al. (Eds.). La salud como derecho ciudadano: perspectivas y propuestas desde América Latina. Lima: Universidad Peruana Cayetano Heredia, 2003. p.137-52.

LYRA-DA-FONSECA, J.L.C. Homens, feminismo e direitos reprodutivos no Brasil: uma análise de gênero no campo das políticas públicas (2003-2006). 2008. Tese (Doutorado em Saúde Pública) - Departamento de Saúde Coletiva, Centro de Pesquisas Aggeu Magalhães, Fundação Oswaldo Cruz, Recife. 2008.

MACHADO, M.F.; RIBEIRO, M.A.T.; MARTINS, M.H.M. Produzindo sentidos de saúde entre homens jovens de uma comunidade de pescadores. In: SEMINÁRIO NACIONAL HOMENS E MASCULINIDADES: PRÁTICAS DE INTIMIDADE E POLÍTICAS PÚBLICAS, 6., 2010, Recife. Anais... Recife, 2010. p.34. 
MINAYO, M.C.S. O desafio da pesquisa social. In: (Org.). Pesquisa social: teoria, método e criatividade. 28.ed. Petrópolis: Vozes, 2009. p.9-29.

MONTERO, M. Hacer para transformar: el método en la psicología comunitaria. Buenos Aires: Paidós, 2006.

PASSOS, I.C.F. et al. Perfil psicossocial da clientela atendida em serviços de psicologia: o "Formulário para Cadastro de Conjuntos Sociais". Plural, v.13, n.19/ 20, p.173-214, 2004

SCHRAIBER, L.B. et al. Necessidades de saúde e masculinidades: atenção primária no cuidado aos homens. Cad. Saude Publica,v.26, n.5, p.961-70, 2010. Disponível em: <http://www.scielosp.org/scielo.php?script=sci_arttext\& pid=S0102-311X2010000500018\&lng=en\&nrm=iso > . Acesso em: 4 jan. 2012. http://dx.doi.org/10.1590/S0102-311X2010000500018.

SCHRAIBER, L.B.; GOMES, R.; COUTO, M.T. Homens e saúde na pauta da Saúde Coletiva. Cienc. Saude Colet., v.10, n.1, p.7-17, 2005. Disponível em: $<$ http://www.scielo.br/scielo.php?script=sci_arttext\&pid=S1413-812 $32005000100002 \& \operatorname{lng}=$ en\&nrm=iso > . Acesso em: 25 abr. 2010.

SIMIÃO, F.C.N. Ele só chega nas últimas, quando não tem mais jeito: atenção à sexualidade e à saúde reprodutiva dos homens nos discursos de profissionais do Programa Saúde da Família em Recife. 2010. Dissertação (Mestrado em Psicologia) - Departamento de Psicologia, Centro de Filosofia e Ciências Humanas, Universidade Federal de Pernambuco, Recife. 2010.

SINDICATO DOS PRODUTORES DE AÇÚCAR E ÁLCOOL DE ALAGOAS SINDAÇÚCAR - AL (2007). Geração de empregos diretos. Disponível em: $<$ http://www.sindacucar-al.com.br/gerempregdiret.htm >. Acesso em: 25 nov. 2010.

SPINK, M.J.P. Linguagem e produção de sentidos no cotidiano. Porto Alegre: EDIPUCRS, 2004.

(Org.). Práticas discursivas e produção de sentidos no cotidiano: aproximações teóricas e metodológicas. 2.ed. São Paulo: Cortez, 2000.

VALDÉS, T.; OLAVARIA, J. (Eds.). Masculinidades y equidad de género en América Latina. Santiago de Chile: Flasco, 1998.

VILLELA, W. Gênero, saúde dos homens e masculinidades. Cienc. Saude Colet., v.10, n.1, p.18-34, 2005. Disponível em: <http://www.scielo.br/ scielo.php?script $=$ sci_arttext\&pid $=$ S1413-81232005000100008 $\& \operatorname{lng}=\mathrm{en} \& \mathrm{nrm}=\mathrm{iso}>$. Acesso em: 25 mar. 2011.

VILLELA, W.; MONTEIRO, S.; VARGAS, E. A incorporação de novos temas e saberes nos estudos em saúde coletiva: o caso do uso da categoria gênero.

Cienc. Saude Colet., v.14, n.4, p.997-1006, 2009. 
MACHADO, M.F.; RIBEIRO, M.A.T. Los discursos de los jóvenes sobre el acceso a los servicios de salud. Interface - Comunic., Saude, Educ., v.16, n.41, p.343-55, abr./jun. 2012.

Son presentadas algunas reflexiones sobre los significados producidos por hombres jóvenes de una comunidad de pescadores en el nordeste de Brasil sobre el uso de servicios de atención básica en su área. Se parte de informaciones obtenidas a través de la observación participante; de los datos de los servicios de Salud Municipal y de los grupos focales realizados con jóvenes. Se identifica entre los jóvenes un creciente consumo de alcohol y otras drogas psicoactivas y una preferencia, entre los membros de la comunidad, a utilizar sus conocimientos legos de los cuidados de la salud y no el servicio de la red social, buscándolo sólo cuando hay un empeoramiento y/o se siente dolor. Así pues, hay la necesidad de ampliar el debate sobre la masculinidad teniendo en cuenta su relación con la salud del hombre.

Palabras clave: Hombres jóvenes. Producción de significado. Atención primaria de salud.

Recebido em 16/06/11. Aprovado em 21/01/12. 
